\title{
LA BATAlla GLOBAL POR EL ALMA DEL CAPITALISMO
}

Luis Esteban G. Manrique ${ }^{1}$

El gigante informático norteamericano Apple vale hoy en bolsa unos 350.000 millones de dólares, 20.000 millones más que la segunda compañía del país, ExxonMobil, y también más que los 32 mayores bancos de la zona euro juntos. Sin embargo, Apple apenas tiene 47.000 empleados en todo el mundo, 30.000 de los cuales trabajan en EE.uU., pero ninguno de ellos en plantas de ensamblaje. Todos sus famosos productos -los iMac, iPod, iPad, iPhone- son fabricados en China por la contratista taiwanesa Foxconn, para la que trabajan casi un millón de personas, 250.000 de ellas dedicadas en exclusiva a los artilugios electrónicos de la compañía de la manzana.

La externalización (offshoring) a países de mano de obra barata es una de las razones que explica el abultado déficit comercial de la superpotencia en productos manufacturados: 500.000 millones de dólares en 2010. Hace 10 años, EE.uu. tenía un superávit comercial en productos de alto valor tecnológico añadido; el año pasado tuvo un déficit de 81.000 millones de dólares.

Si en algo están de acuerdo los analistas sobre la crisis de deuda soberana de la zona euro es que todas las soluciones financieras no servirán de nada si sus economías no vuelven a crecer y a generar empleo. Descubrir y crear "vetas de empleo" se está convirtiendo en uno de los grandes desafíos de las economías desarrolladas para mantener su competitividad ante la pujanza de los países emergentes.

Hoy las 10 mayores economías de Asia tienen un PIB conjunto mayor que el de la ue o el de eE.uu. En 2019 el '10-G' asiático representará el

\footnotetext{
1 Redactor jefe del Informe Semanal de Política Exterior, (Madrid, España). Es analista de política y economía internacionales.
} 
50\% del PIB global, según el Peterson Institute for Internacional Economics, que proyecta además que el PIB agregado de las economías emergentes y en desarrollo crecerá a una tasa anual del 5,6\% en los próximos 20 años. Desde 1978, China ha multiplicado por 10 su participación en el comercio mundial, del $0,7 \%$ al actual $7,7 \%$, mientras que en los últimos 60 años la de Ee.uu. se ha reducido del 28 al 14\%.

Como ha recordado Gordon Brown, en un momento de su historia Europa representaba el 50\% de la economía mundial. En 1980 había caído al 25\% y hoy es el 19\%. En 2030 podría ser apenas el 11\% y en 2050 el 7\%, algo menos que América Latina. A pesar del éxito exportador de Alemania en países como China, Rusia o Brasil, sólo el 8\% de las exportaciones de la uE -frente al 15\% de las de EE.uU.- van a las ocho economías emergentes de mayor crecimiento. Hoy el sector manufacturero británico representa el 12\% del PIB, la mitad que en los primeros años noventa.

EE.UU. ha perdido 5,7 millones de puestos de trabajo en el sector manufacturero en la última década, una contracción del 30\%. El McKinsey Global Institute prevé un crecimiento del 0\%, en el mejor de los casos, hasta 2020 en ese sector. La globalización -que hasta hace poco se la consideraba capaz de generar un círculo virtuoso de crecimiento global- está comenzando a desindustrializar a marchas forzadas a muchas economías desarrolladas cuyas exportaciones de valor agregado han perdido competitividad por una conjunción fatal de altos costes laborales, baja productividad, sustitución de mano de obra por máquinas o una combinación de todos esos factores.

En los últimos 10 años se han cerrado 57.000 plantas industriales en EE.uU., mientras que sus multinacionales crearon 2,2 millones de empleos en el exterior, reduciendo en 2,9 millones sus empleos en el país. En la década pasada, en buena parte de eE.uu. y la ue el empleo se mantuvo por una doble burbuja: la crediticia, inflada por los bajos tipos de interés, y la inmobiliaria. Ese espejismo se desvaneció con la crisis de 2008. Hoy el desempleo entre jóvenes norteamericanos de entre 20 y 24 años está en el 14,5\%. Entre 1997 y 2007 la producción del sector manufacturero aumentó un 3,9\% anual, pero dado 
que la productividad lo hizo un 6,8\% en ese mismo periodo, millones de empleos se perdieron. Si esas tasas se repiten hasta 2020 se perderán 2,3 millones más, mientras que la economía necesita crear 20 millones de empleo para volver a las tasas de los años noventa (4,5\%).

Andy Grove, ex presidente de Intel, y Jeffrey Immelt, ceO de General Electric, han firmado un manifiesto en que sostienen que es "absolutamente prioritario" que EE.uU. siga siendo una gran potencia industrial en sectores como la siderurgia, la química, micro y nano electrónica, biotecnología industrial, materiales avanzados y fotónica. Según Grove, la formación de una fuerza laboral capacitada tarda décadas en desarrollarse pero se puede perder en apenas 10 años. Cuando un ecosistema industrial se degrada, toda la cadena de innovación sufre las consecuencias.

Dado que los servicios sólo suponen el 20\% del comercio mundial, cada vez son mayores los analistas y expertos que creen imprescindible algún tipo de política industrial adecuada a los tiempos que corren y que permita una convergencia de inversiones públicas y privadas en I + D para impulsar la innovación. A pesar de su enorme valor en bolsa, Facebook sólo emplea a unas 2.000 personas en todo el mundo y Google a 29.000. En cambio, incluso después de su reestructuración, General Motors, que vale una fracción de Google, emplea a unos 200.000 trabajadores, una cifra que se multiplica varias veces si se toma en cuenta a todas las industrias subsidiarias implicadas en su cadena de producción.

En Ee.uu. la industria manufacturera es responsable del $70 \%$ de la I + D privada y emplea al $64 \%$ de los científicos e ingenieros del país. Vikram Dalal, profesor de ingeniería informática de la Universidad Estatal de Iowa, cree que EE.uu. corre el riesgo de entrar en una "espiral autodestructivo": con menos ingresos tributarios, los Estados dejan de invertir en educación de calidad en las universidades públicas. 
En Los Angeles Times Dalal explica cómo una compañía de celdas fotovoltaicas de Massachusetts para la que trabajaba, Evergreen Solar, cerró una de sus plantas en ese Estado, incluida su división de I + D, para trasladarla a China porque las autoridades chinas le ofreció terrenos gratuitos, agua gratuita, energía subvencionada, mínimas exigencias medioambientales y 30 millones de dólares de capital riesgo a tipos muy bajos.

Sin infraestructura industrial eE.uU. podría volver a ser un país agrícola. Los hedge funds ya están apostando por esa posibilidad: en los últimos cinco años, la tierra agrícola de Iowa ha triplicado su valor. La administración de Barack Obama ha creado la Advanced Manufacturing Partnertship, que coordina los esfuerzos del mundo académico, la empresa privada y el gobierno federal para impulsar industrias tecnológicas de vanguardia que eviten ese proceso. Desde la Segunda Guerra Mundial las inversiones federales en investigación científica han sido cruciales par el desarrollo de la industria aeroespacial, la electrónica, la informática y la biotecnología.

En Europa está ocurriendo algo similar. Un reciente informe del think tank Bruegel de Bruselas, defiende algo que hasta hace unos años era una herejía en los círculos económicos ortodoxos: relanzar las políticas industriales. Durante mucho tiempo se pensaba que si el mercado estaba destruyendo empleos en un sector era absurdo llevarle la contraria. Lawrence Summers, ex asesor económico de Obama, sostiene por ejemplo que la industria manufacturera no merece un trato especial o diferenciado de los poderes públicos.

Hasta hace poco cualquier alusión a "políticas industriales" resultaba tóxica en una campaña electoral. Hoy las cosas han cambiado. En los últimos dos años, el gobierno federal ha inyectado 2.500 millones de dólares del paquete de estímulos fiscales a unas 30 compañías que están desarrollando baterías para vehículos eléctricos. En 2009 EE.uU. fabricaba menos del $2 \%$ de las baterías de ion-litio en el mundo. En 2015, gracias a las ayudas públicas al sector, esa cifra podría llegar al $40 \%$. 
En la ue las políticas de competencia ven con malos ojos políticas públicas que distorsionen el libre funcionamiento el mercado al "elegir ganadores" porque exponen al Estado al riesgo de ser capturado -y corrompido- por intereses sectoriales y comportamientos rentistas que se aprovechan de subsidios, acceso privilegiado a licitaciones públicas o del proteccionismo a determinadas compañías o industrias. Si los países comunitarios compiten para ofrecer los mayores subsidios, los beneficiarios son los accionistas, no los contribuyentes. Esa es la razón por la que la Bruselas impone límites estrictos a lo que llama "ayudas estatales".

Pero según señala el informe Rethinking industrialpolicy de Bruegel, hay buenas razones para reconsiderar las cosas: sin intervención de los gobiernos para estimular la inversión en sectores como las energías renovables, la tendencia natural de la industria es mantener el statu quo. Pero lo más importante, señala, es que potencias emergentes como China, India o Brasil tiene políticas industriales muy activas. El Banco Nacional de Desarrollo de Brasil (BNDEs), que provee créditos blandos para proyectos industriales y de infraestructuras, por ejemplo, tiene hoy un presupuesto mayor que el del Banco Mundial.

Según Carl Levin, senador demócrata por Michigan, uno de los Estados más golpeados por el declive de la industria del automóvil, sostiene que el contexto exterior lo ha cambiado todo: "nuestras compañías no están compitiendo con otras compañías en China, Corea o Japón sino con los gobiernos que las apoyan [...] Es ingenuo creer que lo único que tenemos que hacer es dejar que los mercados funcionen por sí solos".

Por su parte, Ian Bremmer, presidente de la consultora Eurasia Group, describe en su libro The end of the free market (2010) la que llama "la batalla global por el alma del capitalismo" y en la que están enzarzados los países que practican el laissez-faire y los que confían más en el "capitalismo de Estado", un sistema en el que la economía se subordina a los objetivos políticos de los gobiernos. La crisis de 2008, según el autor, ha producido una transferencia global 
del poder de las capitales de las finanzas a las capitales del poder político: de Shangai a Pekín, de São Paulo a Brasilia, de Bombay a Nueva Delhi, de Nueva York a Washington...

En los países emergentes, pocos gobiernos creen que los mercados por sí solos vayan a cerrar la brecha que los separa de los países ricos. A tipos de cambio de mercado, el PIB per cápita de Ee.uu. es de 47.170 dólares, mientras que el de China es de 4.250; el de India, 1.340; el de Rusia, 9.910 y el de Brasil, 9.390. En poder paritario de compra la diferencia es menor, pero no demasiado. En 2008, el Banco Mundial estimó que China debe crecer al 9,5\% anual sólo para mantener una tasa constante de empleo.

El nuevo capitalismo de Estado no implica el resurgimiento en el siglo xxi de la planificación socialista centralizada del comunismo del siglo xx. Bremmer lo considera más bien como una forma de capitalismo burocráticamente organizado y que cada gobierno practica a su manera sin que lo sustente una ideología política o una estrategia económica coherente.

El mayor exponente de ese modelo es China. Tras la caída de la Unión Soviética, el Partido Comunista Chino ( $\mathrm{PCCH}$ ) se hizo consciente de que si el sistema era incapaz de generar prosperidad para el pueblo chino, sus días en el poder estaban contados. El Estado simplemente no podía ordenar a la economía que creciera a los ritmos que más le conviniera al partido: sólo liberando las energías empresariales e innovadoras de su vasta población el país podría crecer... y el partido sobrevivir.

Pero el modelo escogido no fue un laissez-faire irrestricto sino un nuevo modelo híbrido en el que el Gobierno utilizaría las empresas estatales para gestionar la explotación de los recursos estratégicos y crear y mantener un gran número de puestos de trabajo en el sector privado proveyéndoles subsidios, créditos, barreras arancelarias e imponiendo diversos límites a la competencia. 
En un símil futbolístico, el Gobierno no es el árbitro: es el dueño del estadio, patrón de los árbitros y de los jugadores, principal accionista de los clubes y manipulador de la cobertura informativa de los medios. Los espectadores se benefician de un nivel limitado de competencia, pero el Estado amaña los resultados para favorecer sus intereses. El primer ministro chino, Wen Jiabao, describió así el sistema en una entrevista en Newsweek: "nos aseguramos que tanto la mano invisible como visible tengan plena capacidad para regular a las fuerzas del mercado".

Esa tendencia se aprecia sobre todo en la industria extractiva de recursos naturales. Tres cuartas partes de las reservas de petróleo del mundo están en manos de empresas estatales. Las multinacionales privadas occidentales tienen apenas el 10\%. La mayor de ellas, Exxon Mobil, ocupa el puesto 15 entre las mayores del mundo, mientras que las 14 estatales más grandes controlan veinte veces más petróleo y gas que las ocho principales multinacionales. El principal proveedor de gas de Europa es Gazprom (90\% del Estado ruso) y el segundo la argelina Sonatrach (del Estado argelino). Y cuando no lo hacen directamente a través de la propiedad los Gobiernos buscan participar de los dividendos que generan las materias primas, hoy en un "superciclo" de precios altos, a través de impuestos y regalías.

Actualmente, tres de los cuatro bancos más grandes del mundo son estatales, todos ellos chinos, como también lo es la mayor compañía telefónica del mundo: China Mobile. América Latina está llena de esas macroempresas estatales. Algunas son ineficientes y otras extraordinariamente eficientes: la mexicana Pemex y la venezolana PDVSA son ejemplos de las primeras; la brasileña Petrobras, la chilena Codelco y la colombiana Ecopetrol de las segundas.

Aunque gigantes como la mexicana Cemex y la brasileña Rio do Vale Doce son compañías privadas. Ambas disfrutan de la protección de sus Gobiernos frente a tomas de control foráneas y la competencia interna. Las rusas Gazprom y Rosneft, que controlan el 90\% de la producción de gas y el 50\% de la de petróleo del país, son al mismo tiempo el brazo energético de la política exterior del Kremlin y la 
principal fuente de financiación de la clase dirigente. Holdings estatales controlan además la industria aeroespacial, nuclear, los astilleros y las exportaciones de armamento. El primer ministro Vladimir Putin es presidente del Banco Nacional de Desarrollo (veB). Sin un permiso oficial, ninguna empresa extranjera puede tener más del 10\% de una compañía que explote recursos naturales estratégicos.

En India, aunque el sector público ha caído hasta el 25\% del PIB, frente al $50 \%$ en los primeros años ochenta, el Estado posee más del 59\% de las 40 mayores compañías del país y es propietario de 200 empresas con operaciones en los sectores del acero, las telecomunicaciones, la energía y los hidrocarburos. El comercio exterior indio sólo compromete el 25\% del Рів frente al 40\% en China, lo que inmuniza en cierta medida a la economía de choques externos.

En Arabia Saudí el sector privado, que representa el $45 \%$ del PIB, depende del Estado - al que no le interesa que surjan poderes económicos paralelos- para casi todo. El Estado maneja directamente los ingresos petroleros y establece los objetivos estratégicos de la petrolera Saudi Aramco. Algo similar ocurre en Irán y en todos los demás "petro-Estados" de golfo Pérsico/Arábigo.

Desde 2004 unas 117 empresas estatales de Brasil, Rusia, India y China aparecen en la lista Forbes Global 2000 de las mayores del mundo por ventas, beneficios, activos y valor en bolsa. En 2009 las chinas IсBC, China Mobile y PetroChina figuraron entre las cinco mayores del mundo.

La crisis de 2008 ha agudizado esa tendencia al desacreditar entre muchos países en desarrollo los excesos de la desregulación, especialmente del sistema financiero, aumentando el atractivo de modelos intervencionistas alternativos a un sistema que prioriza los beneficios inmediatos ignorando los riesgos económicos y financieros a largo plazo. Bremmer critica las distorsiones que introduce el "capitalismo de Estado" en la economía global y describe sus muchas debilidades estructurales, pero admite que plantea un desafío a largo plazo al capitalismo de libre mercado. 
El problema para los países desarrollados es que todo ello equivale a una competencia que no puede controlar y para la que tendrá que encontrar respuestas. Alemania parece ser un buen ejemplo a seguir: su ratio de exportaciones en relación al PIB duplica al de EE.UU., a pesar de que los salarios del sector manufacturero son un 50\% más altos que los norteamericanos.

El informe de Bruegel insiste, por su parte, que si la ue quiere crecer y competir globalmente la Comisión Europea tendrá que permitir mayores ayudas sectoriales de los países miembro si estas están diseñadas para fomentar la innovación y la producción y si son compatibles con las políticas de competencia, que deben evitar un enfoque excesivamente "legalista" al analizar los costes y beneficios de las ayudas estatales. El debate ya no es, por tanto, si se deben implementar o no políticas industriales, sino de qué tipo deben ser y de qué modo debe aplicarse una intervención gubernamental inteligente en la economía. 
